\title{
Early enteral nutrition in critical illness: a full economic analysis using US costs
}

This article was published in the following Dove Press journal:

ClinicoEconomics and Outcomes Research

22 August 2013

Number of times this article has been viewed

\section{Gordon S Doig' \\ Hélène Chevrou-Séverac ${ }^{1,2}$ \\ Fiona Simpson' \\ 'Northern Clinical School Intensive Care Research Unit, University of Sydney, Sydney, NSW, Australia; ${ }^{2}$ Global Head of Health Economics, Nestlé Health Sciences, Vevey, Switzerland}

Correspondence: Gordon S Doig Royal North Shore Hospital, Intensive Care Unit, Pacific Hwy, St Leonards, NSW, 2065, Australia

Tel +6I 294632607

Tel +6I 294632056

Email gdoig@med.usyd.edu.au
Purpose: Although published meta-analyses demonstrate patient survival may be improved if enteral nutrition (EN) is provided to critically ill patients within 24 hours of injury or admission to the intensive care unit (ICU), these publications did not investigate the impact of early EN on measures of health care resource consumption and total costs.

Materials and methods: From the perspective of the US acute care hospital system, a cost-effectiveness analysis was undertaken based on a large-scale Monte Carlo simulation $(\mathrm{N}=1,000,000$ trials) of a 1,000-patient stochastic model, developed using clinical outcomes and measures of resource consumption reported by published meta-analyses combined with cost distributions obtained from the published literature. The mean cost differences between early EN and standard care, along with respective $95 \%$ confidence intervals, were obtained using the percentile method.

Results and conclusion: The provision of early EN to critically ill patients is a dominant technology: Patient survival is significantly improved and total costs of care reduced meaningfully. Under conservative assumptions, the total costs of acute hospital care were reduced by US $\$ 14,462$ per patient $(95 \%$ confidence interval US $\$ 5,464$ to US\$23,669). These results were robust, with all sensitivity analyses demonstrating significant savings attributable to the use of early EN, including sensitivity analysis conducted using European cost data.

Keywords: intensive care, costs, cost-effectiveness analysis, nutritional support, critical care, enteral feeding, meta-analysis

\section{Introduction}

The provision of early and appropriate nutrition support to patients during a critical illness or catastrophic injury is accepted to improve health outcomes, ${ }^{1}$ with the majority of international clinical practice guidelines recommending the provision of early enteral (gut) nutrition (EN). ${ }^{2,3,4}$

Although previous systematic reviews and meta-analyses of clinical trials conducted on this topic demonstrated mortality may be reduced if EN is provided to critically ill patients within 24 hours of injury or admission to the intensive care unit (ICU), $, 6,7$ these publications did not investigate the impact of early EN on measures of health care resource consumption and costs. Furthermore, a critical review of previous economic analyses assessing the financial consequences of providing EN to hospital patients found the majority tended to take a narrow focus on up-front acquisition costs of EN, failing to consider the financial implications of downstream health care resource consumption. ${ }^{8}$

The purpose of this current paper was to conduct a full economic analysis, to assess the financial implications of providing early EN (starting EN $<24$ hours from 
injury or ICU admission) to critically ill patients compared with standard care (any form of nutrition support provided $>24$ hours after injury or ICU admission).

\section{Materials and methods}

\section{Context}

Our intensive care research group has previously published systematic reviews and meta-analyses of clinical trials demonstrating that mortality is significantly reduced, if critically ill patients are provided EN within 24 hours of ICU admission or injury compared with standard care, where standard care is defined as any form of nutritional support commenced later than 24 hours from ICU admission or injury. ${ }^{6,7}$ In order to assess the full financial impact of the delivery of early EN during critical illness, this current project updates these meta-analyses to include assessments of the major measures of health care resource consumption: ICU length of stay, duration of invasive mechanical ventilation, and duration of hospital stay.

\section{Type of economic evaluation}

In the context of a significant reduction in mortality attributable to early EN, established by published meta-analyses of clinical trials (odds ratio $=0.34,95 \%$ confidence interval [CI] 0.14 to $\left.0.85, P=0.02, I^{2}=0.0 \%\right),{ }^{7}$ a cost-effectiveness analysis (CEA) was undertaken.

Major measures of resource consumption demonstrating marginal differences between the competing treatment alternatives (early EN versus standard care) were eligible for inclusion in the economic analysis and were combined with costs obtained from the published literature, using a stochastic model with a large-scale Monte Carlo simulation, conducted to estimate the total cost differences and $95 \% \mathrm{CI}$.

\section{Perspective and time horizon}

This CEA was conducted from the perspective of the US acute care hospital system. The time horizon of the analysis was the period from study enrolment (ICU admission) until acute care hospital discharge.

\section{Discounting/indexing of costs}

The US Department of Labor Consumer Price Index (CPI) for Medical Consumers was used to index published US costs to 2012 US funds, based on the specific index rate reported for each year. ${ }^{9}$ In addition, a sensitivity analysis was conducted using a conservative index rate of $4.0 \% .^{10}$

All costs reported in this manuscript were indexed to 2012 US funds, using the CPI, unless explicitly reported otherwise.

\section{Costs of acute care whilst in the ICU}

Cost distributions for acute care whilst admitted to an ICU were obtained from the published literature. Dasta et $\mathrm{al}^{11}$ reported the mean daily costs of care from the perspective of the acute care hospital, for patients admitted to an ICU, using an administrative database composed of 51,009 ICU patients from 253 geographically diverse hospitals across the USA. This database, maintained by NDCHealth, contains patient charges recorded by operational billing systems and is regularly audited for accuracy. ${ }^{11}$ Costs were estimated using hospital-specific cost-to-charge ratios. Hospitals contributing to this study are considered to be representative of the larger US hospital population with regards to geographic location, bed number, and teaching status.

Dasta et $\mathrm{al}^{11}$ found costs to be significantly higher for the first 2 days of ICU admission compared with subsequent days, with significant differences also existing between the major patient groups (medical patient, surgical patient, and trauma patient) and between patients who received invasive mechanical ventilation during their ICU stay compared with patients who did not receive mechanical ventilation. Table 1 presents the relevant cost distribution matrix abstracted from the publication by Dasta et al. ${ }^{11}$

Table I Matrix of the distributions of daily costs of care whilst admitted to the intensive care unit

\begin{tabular}{|c|c|c|c|c|c|c|}
\hline & \multicolumn{2}{|l|}{ Medical patients } & \multicolumn{2}{|l|}{ Surgical patients } & \multicolumn{2}{|l|}{ Trauma patients } \\
\hline & Received MV & Never received MV & Received MV & Never received MV & Received MV & Never received MV \\
\hline Day I & $\$ 8,14 \mid(\$ \$ 5,584)$ & $\$ 5,357(\$ 5,584)$ & $\$ 20,582(\$|4,3| 9)$ & $\$ 9,916(\$ 14,319)$ & $\$ 15,625(\$ 11,955)$ & $\$ 9,062(\$ 11,955)$ \\
\hline Day 2 & $\$ 6,535(\$ 4,678)$ & $\$ 4,783(\$ 4,678)$ & $\$ 7,726(\$ 6,977)$ & $\$ 5,050(\$ 6,977)$ & $\$ 7,414(\$ 6,683)$ & $\$ 4,968(\$ 6,683)$ \\
\hline Day 3 & $\$ 5,703(\$ 4,666)$ & $\$ 4,26$ I $(\$ 4,666)$ & $\$ 6,627(\$ 5,624)$ & $\$ 4,765(\$ 5,624)$ & $\$ 5,880(\$ 5,750)$ & $\$ 4,64$ I $(\$ 5,750)$ \\
\hline plus & & & & & & \\
\hline
\end{tabular}

Notes: Values are expressed as mean costs (standard deviation); indexed to 2012 US Dollars. Costs were abstracted from Dasta et al."

Abbreviation: MV, mechanical ventilation. 


\section{Costs of I day of enteral nutrition}

The costs for the delivery of 1 day of EN to a critically ill patient were established from review of the published literature. A systematic review conducted by Pritchard et al ${ }^{8}$ reported a wide variation in costs, ranging from $£ 7$ per day of EN (1994 UK pounds) to charges of US\$46 per day for pediatric ICU patients (1996 US dollars). This review made specific comments on the poor quality of most studies reporting daily costs of EN and noted that older studies reporting costs may not be relevant due to recent reductions in the purchase price of EN. ${ }^{8}$

A more recent study by Strickland et $a l,{ }^{12}$ which was not included in the review by Pritchard et al, ${ }^{8}$ documented the total costs (purchase costs, supplies used for delivery, and professionals' time) of providing EN to critically ill patients in the US market. ${ }^{12}$ This single-centre study reported the total costs of providing a 7-day postoperative EN course to a medical ICU or trauma patient was US\$245 (2012 US dollars), or US\$35 per day.

To allow for inherent variability between hospitals, and to ensure a conservative overcosting of EN, we inflated these costs by $50 \%$ and assumed a wide standard deviation (SD), in keeping with the SD of other reported medical costs (see Table 1) used in this simulation. The daily cost of EN used in our stochastic model was US\$52.50 per day, with an SD of US\$52.50.

\section{Marginal difference in days of enteral nutrition between early enteral nutrition patients and standard care}

A multicentre survey of international nutrition practices reviewing 2,946 patients admitted to 158 ICUs from 20 countries reported the mean time from ICU admission to starting EN was 46 hours, with the worst performing hospital waiting in excess of 149.1 hours, mean time, to commence EN. ${ }^{13}$

To ensure conservative overcosting of the number of extra days of EN support provided by starting EN within 24 hours of ICU admission, the worst performing hospital case was used. The stochastic model therefore assumes that early EN patients received an additional mean of 6.21 days $(\mathrm{SD}=6.21$ days) of EN compared with standard care patients.

\section{Measures of acute care hospital resource consumption}

By meta-analysis, the net impact of providing early EN was assessed on major measures of resource consumption
(ICU stay, duration of invasive mechanical ventilation, and hospital stay). Only measures demonstrating marginal differences between the competing alternatives $(P$-value $<0.10)$ were considered for inclusion in the stochastic model.

\section{Structure of the stochastic cost model and large-scale Monte Carlo simulation}

Costs of care were estimated using a stochastic model based on the sum of daily cost components, modeled using the gamma distribution with mean $\mu$ and shape $\alpha$, where

$$
\alpha=\operatorname{mean}^{2} / \mathrm{SD}^{2} .
$$

For example, the total costs of acute care for a group of ten trauma patients who received mechanical ventilation and consumed 115 days of care in an ICU (ten patients $\times$ average stay of 11.5 days) and 70 days of $\mathrm{EN}$ would be estimated as the sum of four randomly generated gamma-distributed cost components: ten day-1 ICU costs at G(US\$15,625, US\$11,955) each day plus ten day-2 ICU costs at G(US\$7,414, US\$6,683) each day plus 95 day-3 ICU costs at G(US\$5,880, US\$5,750) each day plus $70 \mathrm{EN}$ costs at G(US\$52.50, US\$52.50) each day, where G(mean, SD). Daily costs for each major patient type abstracted from Dasta et $\mathrm{al}^{11}$ are reported in Table 1.

For each of the 1,000 simulated patients (500 early EN versus 500 standard care) in the stochastic model, measures of resource consumption and costs were estimated for $\mathrm{N}=1,000,000$ episodes of care, to generate stable estimates of costs and confidence intervals. The CEA was based on the net differences in costs between the 1,000,000 simulated patient groups.

All simulations were conducted using $\mathrm{SAS}^{\circledR}$ version 9.2 (SAS Institute, Cary, NC, USA). Meta-analyses were conducted using RevMan 5.2 (The Nordic Cochrane Centre, Copenhagen, Denmark).

\section{Calculation of the mean costs and $95 \%$ confidence intervals}

The mean cost difference of acute care between the competing alternatives (early EN versus standard care), along with $95 \%$ CIs, were obtained using the percentile method. As opposed to bootstrapping, which requires resampling and typically uses fewer trials $(\mathrm{N}=1,000)$, the percentile method does not require correction for bias when applied to large-scale simulations, which typically use more trials (N > 250,000) with no resampling..$^{14}$ 


\begin{tabular}{|c|c|c|c|c|c|c|c|c|c|c|}
\hline \multirow[b]{2}{*}{ Study or subgroup } & \multicolumn{3}{|c|}{ EEN } & \multicolumn{3}{|c|}{ SoC } & \multicolumn{3}{|c|}{ Mean difference } & \multirow{2}{*}{$\begin{array}{c}\text { Mean difference } \\
\text { IV, fixed, } 95 \% \mathrm{Cl} \text { [days] }\end{array}$} \\
\hline & Mean [days] & SD [days] & Total & Mean [days] & SD [days] & Total & Weight & IV, fixed, $95 \% \mathrm{Cl}$ [days] & Year & \\
\hline Chuntrasakul et al ${ }^{18}$ & 8.14 & 6.28 & 21 & 8.35 & 4.78 & 17 & $47.7 \%$ & $-0.21[-3.73,3.31]$ & 1996 & - \\
\hline Pupelis et al $\left.\right|^{19}$ & 13.9 & 14.6 & 30 & 16 & 20.5 & 30 & $7.3 \%$ & $-2.10[-12.86,8.66]$ & 2001 & \\
\hline Kompan et al20 & 15.9 & 9.7 & 27 & 20.6 & 18.5 & 25 & $8.9 \%$ & $-4.70[-12.82,3.42]$ & 2004 & \\
\hline Nguyen et $\mathrm{al}^{21}$ & 11.3 & 2.99 & 14 & 15.9 & 7.11 & 14 & $36.1 \%$ & $-4.60[-8.64,-0.56]$ & 2008 & \\
\hline \multirow[t]{2}{*}{ Total $(95 \% \mathrm{Cl})$} & & & 92 & & & 86 & $100.0 \%$ & $-2.34[-4.76,0.09]$ & & \\
\hline & & & & & & & & & & $\begin{array}{cccc}-10 & -5 & 0 & 5 \\
\text { Favors EEN } & \text { Favors SoC }\end{array}$ \\
\hline
\end{tabular}

Figure I Meta-analysis of ICU length of stay: early enteral nutrition vs standard care.

Notes: Heterogeneity: $\chi^{2}=2.94, \mathrm{~d} f=3(P=0.40) ; I^{2}=0 \%$. Test for overall effect: $Z=1.87(P=0.06)$.

Abbreviations: $\mathrm{Cl}$, confidence interval; EEN, early enteral nutrition; ICU, Intensive Care Unit; IV, inverse variance; SD, standard deviation; SoC, standard of care.

\section{Sensitivity analyses}

Four sensitivity analyses were planned in advance of conducting the primary CEA, and one additional sensitivity analysis was undertaken in response to peer review:

1. The primary CEA analysis was rerun using lognormal distributional assumptions for cost data, instead of gamma distributional assumptions.

2. The primary CEA analysis was rerun using a conservative discount of $4 \%$ per annum, instead of discounting according to the CPI.

3. The primary CEA analysis was rerun for each major patient type (eg, 100\% medical, 100\% surgical, 100\% trauma), instead of using a mixed distribution of patients.

4. The primary CEA analysis was rerun using published daily costs of ICU care and study intervention costs for the European market, instead of published US costs. Based on a microcosting study conducted in the Netherlands, the average total costs of 1 ventilated-ICU day has been reported as a mean $€ 2,349$ with $\mathrm{SD} € 2,206$ and for an unventilated-ICU day as mean $€ 1,835$ with SD $€ 1688,{ }^{15,16}$ indexed to 2012 Euros, using the European Central Bank Harmonised Index of Consumer Prices, Overall Index. ${ }^{17}$

The European costs for 1 day of EN were set to a mean $€ 39.30$ with SD $€ 39.30$, converted from the estimated US costs used in the primary CEA, at the rate of $1 \mathrm{USD}=0.748597$ EUR (mid-market rates, June 13, 2013 at 2:22 am coordinated universal time [UTC]).
5. An additional sensitivity analysis was undertaken assuming zero marginal differences between the treatment alternatives with regards to the major measures of hospital resource consumption. The primary CEA analysis was rerun assuming zero impact on ICU length of stay and mechanical ventilation. The incremental costeffectiveness ratio, and its $95 \% \mathrm{CI}$, was calculated using the percentile method.

\section{Results}

\section{Patient outcomes and measures of resource consumption}

A previously published meta-analysis, based on six clinical trials found to be free of major flaws, demonstrated a statistically significant reduction in mortality attributable to the provision of early $\mathrm{EN}$ (odds ratio $=0.34,95 \% \mathrm{CI} 0.14$ to $\left.0.85, P=0.02, I^{2}=0.0 \%\right)^{7}$

Of the six clinical trials qualifying for inclusion in the primary analysis of mortality, four reported a mean and SD for ICU length of stay, ${ }^{18-21}$ three reported a mean and SD for duration of mechanical ventilation, ${ }^{18,20,21}$ and only two reported a mean and SD for hospital length of stay. ${ }^{19,22}$ Complete details of the included trials are reported elsewhere. $^{7}$

Patients receiving early EN demonstrated a strong trend towards a reduction in duration of ICU stay ( -2.3 days $[95 \%$ CI -4.8 to 0.1 days, $P=0.06, I^{2}=0 \%$ ) (Figure 1 ) and duration of mechanical ventilation ( -2.5 days $[95 \% \mathrm{CI}-5.1$ to 0.1 days,

\begin{tabular}{|c|c|c|c|c|c|c|c|c|c|c|c|c|}
\hline \multirow{2}{*}{ Study or subgroup } & \multicolumn{2}{|c|}{ EEN } & \multicolumn{5}{|c|}{ SoC } & \multicolumn{2}{|l|}{ Mean difference } & \multirow{2}{*}{\multicolumn{2}{|c|}{$\begin{array}{c}\text { Mean difference } \\
\text { IV, fixed, } 95 \% \mathrm{Cl} \text { [days] }\end{array}$}} & \\
\hline & Mean [days] & SD [days] & Total & Mean [days] & SD [days] & Total & Weight & & & & & \\
\hline Chuntrasakul et al ${ }^{18}$ & 5.29 & 6.28 & 21 & 6.12 & 5.32 & 17 & $48.1 \%$ & $-0.83[-4.52,2.86]$ & & & - & \\
\hline Kompan et $\mathrm{al}^{20}$ & 12.9 & 8.1 & 27 & 15.6 & 16.1 & 25 & $13.3 \%$ & $-2.70[-9.71,4.31]$ & & & & \\
\hline \multirow[t]{2}{*}{ Total $(95 \% \mathrm{Cl})$} & & & 62 & & & 56 & $100.0 \%$ & $-2.49[-5.05,0.07]$ & & & & \\
\hline & & & & & & & & & $\frac{1}{-20}$ & $\begin{array}{cc}-10 & 0 \\
\text { Favors EEN }\end{array}$ & $\begin{array}{c}10 \\
\text { Favors SoC }\end{array}$ & 20 \\
\hline
\end{tabular}

Figure 2 Meta-analysis of duration of mechanical ventilation: early enteral nutrition vs standard care.

Notes: Heterogeneity: $\chi^{2}=1.69, d f=2(P=0.43) ; I^{2}=0 \%$. Test for overall effect: $Z=1.91 \quad(P=0.06)$.

Abbreviations: $\mathrm{Cl}$, confidence interval; EEN, early enteral nutrition; IV, inverse variance; SD, standard deviation; SoC, standard of care. 


\begin{tabular}{|c|c|c|c|c|c|c|c|c|c|}
\hline \multirow[b]{2}{*}{ Study or subgroup } & \multicolumn{2}{|c|}{ EEN } & \multicolumn{4}{|c|}{ SoC } & \multirow[b]{2}{*}{ Weight } & \multirow{2}{*}{$\begin{array}{c}\text { Mean difference } \\
\text { IV, fixed, } 95 \% \mathrm{Cl} \text { [days] }\end{array}$} & \multirow{2}{*}{$\begin{array}{cc} & \text { Mean difference } \\
\text { Year } & \text { IV, fixed, } 95 \% \mathrm{CI} \text { [days] }\end{array}$} \\
\hline & Mean [days] & SD [days] & Total & Mean [days] & SD [days] & Total & & & \\
\hline Chiarelli et al $^{22}$ & 69.2 & 32.89 & 10 & 89 & 59.77 & 10 & $10.2 \%$ & $-19.80[-62.08,22.48]$ & 1990 \\
\hline Pupelis et $\mathrm{al}^{19}$ & 35.3 & 22.9 & 30 & 35.8 & 32.5 & 30 & $89.8 \%$ & $-0.50[-17.50,16.50]$ & 2001 \\
\hline \multirow[t]{2}{*}{ Total $(95 \% \mathrm{Cl})$} & & & 40 & & & 40 & $100.0 \%$ & $-2.46[-15.95,11.02]$ & \\
\hline & & & & & & & & & $\begin{array}{cc}1 & 1 \\
-50 & -25\end{array}$ \\
\hline
\end{tabular}

Figure 3 Meta-analysis of hospital length of stay: early enteral nutrition versus standard care.

Notes: Heterogeneity: $\chi^{2}=1.69, d f=I(P=0.4 I) ; I^{2}=0 \%$. Test for overall effect: $Z=0.40(P=0.72)$.

Abbreviations: $\mathrm{Cl}$, confidence interval; $\mathrm{EEN}$, early enteral nutrition; IV, inverse variance; SD, standard deviation; SoC, standard of care.

$\left.P=0.06, I^{2}=0 \%\right]$ ) (Figure 2); however, the hospital length of stay did not differ between the groups $(-2.5$ days $[95 \%$ CI -16.0 to 11.0 days, $\left.P=0.72, I^{2}=0 \%\right]$ ) (Figure 3 ).

The stochastic model was based on the marginal differences in ICU length of stay and duration of mechanical ventilation. Table 2 reports the means and SD used in the stochastic model, along with the results of a 250,000 trial Monte Carlo simulation conducted to establish the accuracy of the ICU stay and duration of mechanical ventilation generated by the model.

\section{Monte Carlo simulation results}

The $\mathrm{N}=1,000,000$ trial, large-scale Monte Carlo simulation of the 1,000-patient stochastic model required 1 hour 30 minutes to execute on a $5.1 \mathrm{GHz}$ Intel $3930 \mathrm{~K}$ processor with 64 GB of memory and six Intel 520 series solid state drives in RAID 0 on an LSI 9265 SCSI controller (Intel Corp, Santa Clara, CA, USA). The 1,000 patients in the stochastic model consumed 11,483 ICU days, resulting in the estimation of $11,483,210,772$ ICU cost-days $(11,483$ days $\times 1,000,000$ trials), resulting in a $117 \mathrm{~GB}$ data file.

Based on the population mix of the clinical trials included in the meta-analysis, $28 \%(389 / 1,000)$ of the patients were surgical ICU admissions, 54\% (534/1,000) were trauma patients, and $8 \%(77 / 1,000)$ of patients were medical. All patients enrolled in the included clinical trials received mechanical ventilation during their ICU stays.

\section{Primary CEA analysis: costs indexed to 2012 US dollars using the CPI, gamma distribution}

The primary CEA revealed a US\$14,462 per patient savings in favor of early EN, with a $95 \%$ CI from US $\$ 5,464$ to US\$23,669 savings per patient.

\section{Sensitivity analyses}

The results of the four initial and one additional sensitivity analyses are summarized:

1. Instead of using the gamma distribution, under lognormal distributional assumptions, the CEA revealed a US\$14,483 savings per patient in favor of early EN, with a 95\% CI from US\$5,457 to US\$23,658 savings per patient.

2. Instead of indexing costs using the CPI, indexing at a conservative rate of $4 \%$ revealed a US\$14,116 savings per patient in favor of early EN, with a 95\% CI from US\$5,305 to US\$23,076 savings per patient.

3. Instead of modeling a mixed patient population based on the composition of patients enrolled into the clinical trials included in the meta-analysis, modeling homogenous populations of patients revealed a savings of US\$13,812 per medical patient (95\% CI US\$5,392 to US\$22,389), a savings of US\$16,150 per surgical patient (95\% CI US\$6,222 to US\$26,297), and a savings of US\$14,265 per trauma patient $(95 \%$ CI US\$5,535 to US\$23,353).

Table 2 Distributions of measures of resource consumption: accuracy of the stochastic model under gamma distributional assumptions

\begin{tabular}{|c|c|c|c|c|c|c|}
\hline & \multicolumn{3}{|c|}{$\begin{array}{l}\text { Inputs to the I,000 patient stochastic model, } \\
\text { obtained from meta-analysis }\end{array}$} & \multicolumn{3}{|c|}{$\begin{array}{l}\text { Estimates generated by } 250,000 \text { trial Monte Carlo } \\
\text { simulation of the I,000 patient stochastic model }\end{array}$} \\
\hline & Early EN & Standard care & Difference & Early EN & Standard care & Difference \\
\hline ICU stay (days) & $10.32(9.49)$ & $12.65(12.72)$ & $-2.34(15.87)$ & $\begin{array}{l}10.31(9.50) \\
n=125,000,000\end{array}$ & $\begin{array}{l}12.65(12.73) \\
n=125,000,000\end{array}$ & $\begin{array}{l}-2.34(15.89) \\
N=125,000,000\end{array}$ \\
\hline Invasive MV (days) & $7.81(12.26)$ & $10.31(7.13)$ & $-2.49(14.18)$ & $\begin{array}{l}7.79(12.28) \\
n=125,000,000\end{array}$ & $\begin{array}{l}10.30(7.14) \\
n=125,000,000\end{array}$ & $\begin{array}{l}-2.5 I(14.21) \\
\mathrm{n}=125,000,000\end{array}$ \\
\hline $\begin{array}{l}\text { Early EN delivery } \\
\text { (days) }\end{array}$ & $6.21(6.2 I)$ & $0(0)$ & $6.21(6.2 I)$ & $\begin{array}{l}6.21(6.20) \\
n=125,000,000\end{array}$ & $0(0)$ & $\begin{array}{l}6.21(6.20) \\
n=125,000,000\end{array}$ \\
\hline
\end{tabular}

Notes: Values are expressed as mean (standard deviation); $\mathrm{n}=$ number of iterations.

Abbreviations: EN, enteral nutrition; ICU, Intensive Care Unit; MV, mechanical ventilation. 
4. Under European cost distributions, the CEA revealed a savings of $€ 5,325$ per patient in favor of early EN (95\% CI $€ 2,475$ to $€ 8,224)$. At current exchange rates $(1 \mathrm{EUR}=1.33474$ USD [mid-market rates, June 16, 2013 at 8:39 pm UTC]), this equates to a US\$7,107 savings per patient in favor of early EN (95\% CI US\$3,303 to US\$10,976).

5. Under the worst-case assumptions of zero marginal differences in the major measures of resource consumption between the treatment alternatives, the incremental cost of providing early EN to all eligible patients was US\$2,499 (95\% CI US\$1,839 to US\$3,786) per life saved.

\section{Discussion and conclusion}

We undertook a full economic analysis to assess the cost implications of providing early EN to adult critically ill patients compared with standard care and found that early EN is dominant: early EN resulted in significantly improved patient survival and significantly reduced costs.

The measures of clinical outcome and health care resource consumption were obtained from a comprehensive meta-analysis of clinical trials known to be free of major methodological flaws. ${ }^{7}$ The costs of care and costs of providing early EN were obtained from the published literature. A meta-analysis demonstrated that provision of early EN significantly improved patient survival, and a large-scale Monte Carlo simulation of a stochastic cost model revealed early EN significantly reduced the overall costs of care by US\$14,462 per patient (95\% CI US\$5,464 to US\$23,699). These findings were robust, with all sensitivity analyses demonstrating significant savings attributable to the use of early EN, including the sensitivity analysis conducted using European cost data. The worst-case scenario, assuming a zero effect on ICU stay and duration of mechanical ventilation, demonstrated the costs of saving one additional life by providing early EN to all eligible patients were substantially lower than the arbitrary, accepted threshold of $\$ 50,000$ per additional life-years saved. ${ }^{23}$

A series of a priori defined sensitivity analyses were undertaken to explore alternate decisions regarding the major assumptions behind the primary CEA. Each of these sensitivity analyses agrees with the primary CEA, demonstrating significantly improved survival and reduced costs associated with early EN. Use of the CPI to index reported costs to 2012 US funds controlled for realistic cost increases over time and led to an average index rate of $4.2 \%$ per annum, only slightly higher than the conservative sensitivity analysis index rate of $4 \%$. Additionally, the results obtained by the sensitivity analysis under lognormal distributional cost assumptions were essentially identical to the primary CEA results, conducted under the gamma distribution. A previous publication has demonstrated that distributional assumptions regarding costs may not be as important when large-scale Monte Carlo simulations are conducted compared with smaller simulations $(\mathrm{N}<250,000) .{ }^{24}$ Furthermore, the sensitivity analysis conducted within each patient type (medical, surgical, and trauma) confirmed that savings were not constrained to the unique mix of patients enrolled in the clinical trials included in the meta-analysis, and finally, the analysis conducted under European cost assumptions also supported the primary CEA results that were based on US costs.

Although the cost savings reported by the European-based model appear meaningfully lower than those reported by the US-based model, these differences may be attributable to the different cost-accounting methods used in the US and European costing studies. To estimate US costs of care, Dasta et $\mathrm{al}^{11}$ assumed a broad perspective and included the costs of services offered by departments outside of the ICU whereas Tan et $a 1^{16,25}$ focused on the direct costs of ICU care, treating the ICU as a cost centre within the acute care hospital. It has been previously shown that failure to account for costs incurred by departments outside of the ICU may result in misleading conclusions when evaluating the financial impact of ICU-based health care alternatives. ${ }^{26}$ Full economic assessment of the competing alternatives delivered while a patient is cared for in an ICU requires a broader perspective.

\section{Strengths and limitations}

A recent publication based on a multinational survey reporting data from 193 ICUs around the world, including 57 ICUs in the US, revealed that $25 \%(703 / 2,775)$ of eligible critically ill patients failed to receive appropriate nutritional support within 48 hours of admission to the ICU. ${ }^{27}$ These 703 patients, who were identified as not having absolute contraindications to early EN, experienced clinical outcomes remarkably similar to the patient outcomes reported in the clinical trials included in our stochastic cost model (see Table 2), with the recent survey reporting a mortality rate of $34 \%$, a median ICU stay of 12.4 days (interquartile range [IQR] 8.4 to 22.9), and a median duration of mechanical ventilation of 9.3 days (IQR 5.5 to 19.3). This survey demonstrates there is an identifiable population of contemporary critically ill patients, internationally and in the US, who have the potential to benefit from the intervention evaluated in this economic analysis.

In addition to providing costs from the perspective of the acute care hospital, which includes services offered by 
departments outside of the ICU, the cost matrix reported by Dasta et al $^{11}$ (Table 1) allows for accurate stochastic modeling because specific cost distributions can be assigned to specific patient groups (ventilated, medical, surgical, and trauma) for each ICU day. ${ }^{11}$ Furthermore, these US cost estimates were generated from a robust database containing tens of thousands of transactions, from hundreds of hospitals.

Although the costs of 1 day of EN were based on a single-centre study, ${ }^{12}$ both the daily costs of EN and the extra days of EN attributable to earlier starting times were inflated to improve generalizability and ensure conservative conclusions. Given the margin of savings revealed by all simulations, we are reasonably certain the results are not sensitive to the total costs of providing EN.

Because a CPI for Medical Consumers was not available for the Netherlands, ${ }^{28}$ we elected to index the European costs using the European Central Bank Harmonised Index of Consumer Prices, Overall Index. Although inspection of the US CPI reveals the Medical Consumer Index is not directly linked to the Overall Index, use of the European Harmonised Overall Index resulted in an extremely conservative rate of $1.8 \%$ per annum, thus minimizing potential differences between the groups. A more thorough analysis, using more comprehensive cost estimates obtained from a broader perspective, indexed using a harmonized European Consumer Price Index for Medical Consumers, may be required to draw firm conclusions regarding European costs.

\section{Summary}

We conducted a CEA based on the clinical outcomes and measures of resource consumption obtained from a metaanalysis of multiple clinical trials, with costs obtained from the published literature, and reported from the broader perspective of the acute care hospital system. We found the provision of early EN (started $<24$ hours from injury or ICU admission) to critically ill patients was a dominant alternative compared with standard care: the use of early EN significantly improved patient survival and significantly reduced hospital costs.

\section{Disclosure}

The conduct of this economic analysis is an academic work of the authors. It was not supported by external funding. The interpretation and reporting of the data are the sole responsibilities of the authors.

Dr Doig has received academic research grants from Fresenius Kabi Deutschland GmbH, Baxter Healthcare Pty Ltd, and Nestle Nutrition; consulting fees from Nestle Nutrition, Fresenius Kabi Deutschland $\mathrm{GmbH}$, and Baxter Healthcare Pty Ltd; speaker's honoraria from Nestle Nutrition, Baxter Healthcare Pty Ltd, and Fresenius Kabi Deutschland GmbH; and travel support from Fresenius Kabi Deutschland $\mathrm{GmbH}$, Baxter Healthcare Pty Ltd, and Nestle Nutrition.

During her time as a Visiting Research Fellow in Health Economics with the University of Sydney's Northern Clinical School Intensive Care Research Unit, Dr Hélène ChevrouSéverac's salary was supplied by Nestlé Health Science. She currently works for Nestlé Health Science, Global Headquarters, as Global Head of Health Economics.

Ms Simpson has received academic research grants from Fresenius Kabi Deutschland $\mathrm{GmbH}$ and Baxter Healthcare Pty Ltd; speaker's honoraria from Fresenius Kabi Pty Ltd; and travel support from Fresenius Kabi Deutschland GmbH and Baxter Healthcare Pty Ltd.

The authors report no other conflicts of interest in this work.

\section{References}

1. Martin CM, Doig GS, Heyland DK, Morrison T, Sibbald WJ; Southwestern Ontario Critical Care Research Network. Multicentre, cluster-randomized clinical trial of algorithms for critical-care enteral and parenteral therapy (ACCEPT). CMAJ. 2004;170(2):197-204.

2. McClave SA, Martindale RG, Vanek VW, et al; ASPEN Board of Directors; American College of Critical Care Medicine; Society of Critical Care Medicine. Guidelines for the Provision and Assessment of Nutrition Support Therapy in the Adult Critically Ill Patient: Society of Critical Care Medicine (SCCM) and American Society for Parenteral and Enteral Nutrition (ASPEN). JPEN J Parenter Enteral Nutr. 2009;33(3):277-316.

3. Kreymann KG, Berger MM, Deutz NE, et al; DGEM (German Society for Nutritional Medicine); ESPEN (European Society for Parenteral and Enteral Nutrition). ESPEN Guidelines on Enteral Nutrition: Intensive care. Clin Nutr. 2006;25(2):210-223.

4. Doig GS, Simpson F, editors. Evidence-Based Guidelines for Nutritional Support of the Critically Ill: Results of a Bi-National Guideline Development Conference. Sydney: EvidenceBased.net; 2005.

5. Heyland DK, Dhaliwal R, Drover JW, Gramlich L, Dodek P; Canadian Critical Care Clinical Practice Guidelines Committee. Canadian clinical practice guidelines for nutrition support in mechanically ventilated, critically ill adult patients. JPEN J Parenter Enteral Nutr. 2003;27(5): 355-373.

6. Doig GS, Heighes PT, Simpson F, Sweetman EA. Early enteral nutrition reduces mortality in trauma patients requiring intensive care: a metaanalysis of randomised controlled trials. Injury. 2011;42(1):50-56.

7. Doig GS, Heighes PT, Simpson F, Sweetman EA, Davies AR. Early enteral nutrition, provided within $24 \mathrm{~h}$ of injury or intensive care unit admission, significantly reduces mortality in critically ill patients: a meta-analysis of randomised controlled trials. Intensive Care Med. 2009;35(12):2018-2027.

8. Pritchard C, Duffy S, Edington J, Pang F. Enteral nutrition and oral nutrition supplements: a review of the economics literature. JPEN $J$ Parenter Enteral Nutr. 2006;30(1):52-59.

9. US Bureau of Labor Statistics. 2013 Consumer Price Index Detailed Report: Medical Care Consumer Price Index-All Urban Consumers. Washington, DC: US Bureau of Labor Statistics; 2013. Available from: http://data.bls.gov/cgi-bin/surveymost?cu. Accessed June 27, 2013. 
10. Alban A, Gyldmark M, Pedersen AV, Søgaard J. The Danish approach to standards for economic evaluation methodologies. Pharmacoeconomics. 1997;12(6):627-636.

11. Dasta JF, McLaughlin TP, Mody SH, Piech CT. Daily cost of an intensive care unit day: the contribution of mechanical ventilation. Crit Care Med. 2005;33(6):1266-1271.

12. Strickland A, Brogan A, Krauss J, Martindale R, Cresci G. Is the use of specialized nutritional formulations a cost-effective strategy? A national database evaluation. JPEN J Parenter Enteral Nutr. 2005; 29(Suppl 1):S81-S91.

13. Cahill NE, Dhaliwal R, Day AG, Jiang X, Heyland DK. Nutrition therapy in the critical care setting: what is "best achievable" practice? An international multicenter observational study. Crit Care Med. 2010;38(2):395-401.

14. Greenland $\mathrm{S}$. Interval estimation by simulation as an alternative to and extension of confidence intervals. Int J Epidemiol. 2004;33(6): 1389-1397.

15. Al MJ, Hakkaart L, Tan SS, Bakker J. Cost-consequence analysis of remifentanil-based analgo-sedation vs conventional analgesia and sedation for patients on mechanical ventilation in the Netherlands. Crit Care. 2010;14(6):R195.

16. Tan SS, Hakkaart-van Roijen L, Al MJ, et al. Review of a large clinical series: a microcosting study of intensive care unit stay in the Netherlands. J Intensive Care Med. 2008;23(4):250-257.

17. Harmonised indices of consumer prices, breakdown by purpose of consumption: The Netherlands. [webpage on the Internet]. Frankfurt: European Central Bank; 2013. Available from: http://www.ecb.int/stats/ prices/hicp/html/hicp_coicop_anr_NL_2013.en.html. Accessed June 13, 2013.

18. Chuntrasakul C, Siltharm S, Chinswangwatanakul V, Pongprasobchai T, Chockvivatanavanit S, Bunnak A. Early nutritional support in severe traumatic patients. J Med Assoc Thai. 1996;79(1):21-26.

19. Pupelis G, Selga G, Austrums E, Kaminski A. Jejunal feeding, even when instituted late, improves outcomes in patients with severe pancreatitis and peritonitis. Nutrition. 2001;17(2):91-94.
20. Kompan L, Vidmar G, Spindler-Vesel A, Pecar J. Is early enteral nutrition a risk factor for gastric intolerance and pneumonia? Clin Nutr. 2004;23(4):527-532.

21. Nguyen NQ, Fraser RJ, Bryant LK, et al. The impact of delaying enteral feeding on gastric emptying, plasma cholecystokinin, and peptide YY concentrations in critically ill patients. Crit Care Med. 2008;36(5): 1469-1474.

22. Chiarelli A, Enzi G, Casadei A, Baggio B, Valerio A, Mazzoleni F. Very early nutrition supplementation in burned patients. Am J Clin Nutr. 1990;51(6):1035-1039.

23. Braithwaite RS, Meltzer DO, King JT, Leslie D, Roberts MS. What does the value of modern medicine say about the $\$ 50,000$ per qualityadjusted life-year decision rule? Med Care. 2008;46(4):349-356.

24. Doig GS, Simpson F. Early parenteral nutrition in critically ill patients with short-term relative contraindications to early enteral nutrition: a full economic analysis of a multicentre randomized controlled trial based on US costs. Clinicoecon Outcomes Res. 2013;5:369-379.

25. Tan SS, Bakker J, Hoogendoorn ME, et al. Direct cost analysis of intensive care unit stay in four European countries: applying a standardized costing methodology. Value Health. 2012;15(1):81-86.

26. Inman KJ, Sibbald WJ, Rutledge FS, Clark BJ. Clinical utility and cost-effectiveness of an air suspension bed in the prevention of pressure ulcers. JAMA. 1993;269(9):1139-1143.

27. Cahill NE, Murch L, Jeejeebhoy K, et al. When early enteral feeding is not possible in critically ill patients: results of a multicenter observational study. JPEN J Parenter Enteral Nutr. 2011;35(2):160-168.

28. de Haan J, Kleima F. Medical care price and quantity indexes: Dutch practice and unresolved issues. Presented at: the Ninth UN International Working Group on Price Indices: Ottawa Group Meeting; May 14-16; 2006; London, UK.
ClinicoEconomics and Outcomes Research

\section{Publish your work in this journal}

ClinicoEconomics \& Outcomes Research is an international, peerreviewed open-access journal focusing on Health Technology Assessment, Pharmacoeconomics and Outcomes Research in the areas of diagnosis, medical devices, and clinical, surgical and pharmacological intervention. The economic impact of health policy and health systems

\section{Dovepress}

organization also constitute important areas of coverage. The manuscript management system is completely online and includes a very quick and fair peer-review system, which is all easy to use. Visit http://www.dovepress.com/testimonials.php to read real quotes from published authors. 